\title{
La dinámica cultural en un contexto pluriétnico: el caso de Quebec
}

\author{
Laura LÓPEZ MORALES \\ Universidad Nacional Autónoma de México
}

\begin{abstract}
La diversité des origines ethniques et culturelles des Québécois ajoute à la complexité de vivre ensemble. S'il est vrai que la société québécoise en est une d'accueil et d'ouverture, sa diversité ethnoculturelle est un phénomène qui continuera de s'accentuer, en fonction du nombre des nouveaux arrivés qui feront le projet de vivre au Québec.
\end{abstract}

Christian Giguère

Los retos de las sociedades actuales, sobre todo en el primer mundo, se definen en gran medida en función de las cuestiones étnicas ya que la vieja concepción de cultura, en vez de aglomerar a una comunidad en torno de valores compartidos por tradición, hoy día tiende más bien a propiciar la reivindicación de las diferencias identitarias entre los diversos grupos que integran el tejido social.

La sociedad canadiense, en general, constituye un ejemplo por demás paradigmático de esta problemática. Nosotros nos centraremos en el caso particular de la provincia de Quebec para subrayar los rasgos más característicos de la dinámica cultural que se genera por la presencia de grupos étnicos de diversos orígenes que interactúan en un mismo espacio.

\section{Antecedentes inmediatos}

Una vez creada la Confederación, en virtud del acta de Unión de 1840, la llegada a Canadá de minorías extranjeras no francesas ni británicas empieza a registrarse de manera más marcada hacia fines de ese siglo. A lo largo del XX, diferentes oleadas favorecidas por las guerras y otras coyunturas políticas y económicas acentúan el fenómeno con la incorporación de grupos de procedencia ya no sólo europea, sino también asiática, africana y americana. Esta dinámica migratoria ha sido considerablemente alentada por las políticas federales y provinciales, pero fue hasta fechas recientes, es decir las últimas tres décadas del siglo pasado, cuando tanto las instancias oficiales como 


\section{$182 \square$ LA DINÁMICA CULTURAL EN UN CONTEXTO PLURIÉTNICO}

las esferas de intelectuales y académicos acometieron la tarea de analizar, desde una perspectiva de estudio, las implicaciones y los retos de esta realidad. Si bien es cierto que, en sus inicios, los acercamientos científicos al fenómeno habían estado encabezados por sociólogos y antropólogos centrados sobre todo en el presente, es preciso reconocer que las investigaciones realizadas en estas disciplinas más tarde abrieron algunas direcciones que sirvieron de plataforma para los trabajos de los historiadores que adoptaron entonces una perspectiva diacrónica.

Por otra parte, el camino recorrido en las últimas décadas por los estudiosos ${ }^{1}$ de este fenómeno pone de manifiesto las dificultades encontradas simplemente en la definición del campo de análisis. Y lo que primero salta a la vista es que más que afirmaciones hay que formular una serie de interrogantes para circunscribir dicho universo, ${ }^{2}$ sin dejar de matizar las variables que la realidad impone.

Dicho lo anterior, y en virtud de que nuestro campo de competencia no es el de ninguna de esas ciencias, conviene precisar que nos limitaremos a señalar las líneas más visibles de esta evolución para entender, en el contexto actual, quiénes son y cómo interactúan los actores de la vida cultural en Quebec.

\section{En realidad, nada nuevo bajo el sol}

Para entender la dinámica generada en el actual paisaje pluriétnico canadiense, conviene ir un poco atrás en el tiempo y evocar como antecedente más inmediato que, ante el incremento del flujo migratorio ${ }^{3}$ registrado en la segunda posguerra, el gobierno federal se encargó de redefinir las relaciones entre comunidades mayoritarias y minorías étnicas avecindadas en periodos más recientes. Ése fue también el momento en que se revisó el estatus de los grupos amerindios que, como han demostrado investigaciones recientes, se definen por un acendrado nacionalismo en virtud del cual han reivindicado, en diferentes momentos, su estatuto de pueblos originarios (Salée, 1995: 263-292) y el derecho a la autodeterminación. Con lo anterior, es decir la revisión del estatuto de amerindios y minorías étnicas, lo que se hace es incorporar abiertamente al discurso oficial la ya visible diversidad étnica y cultural del país y así replantear los términos con los que podía definirse la "identidad canadiense".

\footnotetext{
${ }^{1}$ Antropólogos, sociólogos, demógrafos, historiadores, politólogos y geógrafos, cada quien desde su enfoque disciplinario, han compartido sin embargo una serie de conceptos y de categorías de análisis emanados, sobre todo, de las ciencias que abordaron en primer término esta temática; tal es el caso de categorías como: comunidades étnicas, inmigración, aculturación y asimilación.

${ }^{2}$ ¿A quién debe incluirse en el concepto de comunidad cultural o de grupo étnico? ¿Debe estudiarse de la misma manera todos los flujos migratorios registrados en Quebec a lo largo de su historia, sin distinguir el momento en que se produce ni el origen del grupo trasterrado? Éstos son sólo dos ejemplos de las preguntas que, en aras del rigor científico, se impone formular al emprender un estudio serio del tema.

${ }^{3}$ Inmigración que contribuyó considerablemente a relanzar el desarrollo económico, así como a equilibrar la baja de natalidad de la población local.
} 
En el contexto descrito conviene recordar otro factor de primera importancia en la problemática: desde hacía tiempo venía imponiéndose la necesidad de redefinir el estatus de la minoría francófona dentro de la Confederación canadiense y con ello se dio pie a la concepción de la política multiculturalista porque tal medida conllevó el reconocimiento de las demás minorías afincadas en el país. Esto queda consagrado oficialmente en 1971, pero además, por fin se completa la antigua política federal sobre el bilingüismo oficial (Harvey, 1992: 159-174) formulada dos años atrás. Estamos en pleno periodo de la Revolución tranquila, y las relaciones entre la provincia de Quebec y el gobierno central son tensas; durante estas dos décadas todos los estratos sociales quebequenses protagonizan una profunda ebullición y la atmósfera está más bien dominada por los ánimos nacionalistas y por la defensa de la especificidad "francesa", como rasgo distintivo de la provincia frente al resto de la Federación. Para remediar estas tensiones se procede a la creación de la Comisión real de encuesta sobre el bilingüismo y el biculturalismo, iniciativa que, de paso, propició las reivindicaciones enarboladas por las minorías étnicas que reclamaban el reconocimiento de sus aportaciones en el devenir del país (Tacheraeu, 2002). A raíz de la publicación del Informe LaurendeauDunton, emanado de la citada comisión, el gobierno de Pierre-Eliot Trudeau inaugura en 1971 su política sobre el multiculturalismo.

Ahora bien, si de todo el territorio canadiense hacemos una suerte de toma en zoom sobre Quebec, veremos que para entender la evolución de las relaciones entre la mayoría francófona y las minorías étnicas afincadas en la provincia, es necesario retomar los últimos dos aspectos evocados en el párrafo anterior, a saber: la exacerbación del espíritu nacionalista quebequense y la puesta en marcha de una política que otorgaba plenos derechos a las minorías étnicas.

Por otra parte, en la medida en que, desde tiempo atrás, la población francófona tiende a anglicizarse, ${ }^{4}$ para preservar y promover lo que se considera la especificidad quebequense, es preciso que los francófonos de origen reconozcan la pluralidad de las demás minorías culturales asentadas en la provincia. Ante esta constatación, las autoridades locales acabaron por adoptar al respecto medidas similares a las implementadas por el gobierno federal, o sea legitimar la diferencia cultural y promover la inserción de esos nuevos ciudadanos, otorgándoles un estatuto de igualdad. Desde ese momento, las políticas provinciales se orientaron claramente a incrementar la inmigración sin dejar de fomentar la integración de los inmigrantes ya residentes de tiempo atrás.

Según estudios sobre los modos de asentamiento de las primeras oleadas migratorias, estos grupos se distribuyeron en diferentes regiones de la provincia, en una época en que Quebec mismo fue expulsor de considerables contingentes que emigraron hacia Estados Unidos. Ahora bien, los grupos llegados en esos tiempos, y que ya han sido objeto de estudios más especializados, son los judíos y los italianos; hoy en día siguen constituyendo las minorías más numerosas. De ellos se conocen los modos de vida

\footnotetext{
${ }^{4}$ Es decir, que los francófonos aceptan las reglas del bilingüismo y los inmigrantes de la provincia tienden más bien a integrarse en inglés que en francés.
} 
asociativa y algunas estrategias de funcionamiento interno. Por lo general se trata de campesinos o de obreros de origen modesto que no tardaron en participar en la vida sindical y militante de izquierda, lo que, por supuesto, no fue muy bien visto por las autoridades tanto provinciales como federales.

\section{Las implicaciones de la diversidad}

Gérard Bouchard, como muchos otros espíritus acuciosos de nuestros días, sostiene que Quebec, al igual que todo Canadá, está en la situación que viven desde hace medio siglo las sociedades occidentales en cuanto a la "confrontación con la diversidad", dado que ésta pone de manifiesto el criterio étnico en la definición identitaria de los grupos y con ello crea conflictos y tensiones. Al respecto cabe señalar el trabajo realizado en las escuelas canadienses durante las recientes décadas, con el propósito de sensibilizar a niños y jóvenes a esta problemática. Para Bouchard "hablar de mestizaje o de intercambios interculturales no debería evocar nada nuevo en el contexto quebequense, pues esos procesos datan de más de cuatro siglos, como han demostrado muchos trabajos recientes de historia cultural y de etnología" (Bouchard, 1999: 64).

En efecto, si bien es cierto que esta diversidad cultural es una realidad desde los comienzos de la conquista y colonización del actual territorio quebequense, ${ }^{5}$ es en los últimos tiempos cuando esta situación se ha vuelto más compleja por la multiplicidad de factores involucrados: sociales, políticos, económicos, religiosos, culturales, urbanos, laborales, etcétera, por sólo mencionar los más evidentes. Además no se puede perder de vista que los asuntos migratorios son un campo de competencia y responsabilidad a nivel federal y provincial, lo cual complica más aún su tratamiento.

Por otra parte, aunque el permiso para inmigrar al país, y concretamente a la provincia, depende de una serie de criterios minuciosamente calificados, la instalación de los recién llegados asume un amplio espectro de condiciones en función de su origen, formación, edad y experiencia, entre otras variables, y, en la misma medida, la posibilidad de integración dependerá de ese perfil. Hasta el último cuarto del siglo pasado se tenía identificada cerca de una treintena de orígenes étnicos diferentes de minorías culturales asentadas en Quebec. Aquí resulta pertinente señalar que, a pesar de que ciertos grupos tienden a practicar uniones endogámicas, es cada vez más frecuente ver alianzas interétnicas. Las identidades plurales o mestizas constituyen día con día la referencia más común.

En el editorial firmado por Jocelyn Maclure con el que se abre, hace cuatro años, el primer número de Les Cahiers du 27 juin, se nos anuncia el propósito de esa nueva

\footnotetext{
${ }^{5}$ Esta realidad es válida finalmente para todo el continente, pues incluso en las regiones con asentamientos civilizados milenarios, a partir del siglo XVI, el Nuevo Mundo se convirtió en un destino para grandes flujos migratorios y, sobre todo, en las zonas menos pobladas, como el norte y el sur del continente, los principales imperios coloniales promovieron estos desplazamientos.
} 
publicación de establecer un intercambio de ideas y perspectivas entre las generaciones, las que encabezaron las reivindicaciones identitarias de la Revolución tranquila y las que nacieron en esas décadas ya como "quebequenses" y han crecido en la oficialización del multiculturalismo. El diálogo intergeneracional e interétnico tiene como mira transformar a la sociedad, en un contexto de democracia y equidad; y este marco está definido por la pluralidad y la diversidad étnica y cultural (Maclure, 2003). De sumo interés resulta un artículo incluido en la citada revista; el título es de suyo revelador de las prioridades de la joven generación representada por los autores del texto. ${ }^{6} \mathrm{La}$ primera diferencia generacional que constatan es la mencionada anteriormente, y al respecto dicen sin conflicto alguno:

Fuimos socializados como quebequenses y nuestros puntos de referencia ya no tienen gran cosa que ver con la sociedad franco-canadiense o canadiense. Más que canadienses franceses, portugueses, italianos, haitianos, o chilenos residentes en Quebec y confinados a su origen étnico en un Canadá anglosajón, nos convertimos en quebequenses apegados a este rincón de América que es Quebec.

Hijos de la ley $101^{7}$ y de la reforma Parent, crecimos en la estela de los logros de la Revolución tranquila. Estudiamos y vivimos con quebequenses de orígenes diversos en un entorno económico y social donde se permitía todo a aquellos y aquellas que estaban en condiciones de comunicarse en francés. No le tememos a la diversidad pues forma parte de una nuestra identidad. En este sentido, consideramos que es preciso alimentarse de la diversidad si queremos seguir existiendo como quebequenses. Contrariamente a nuestros mayores no nos sentimos colonizados... Estamos orgullosos de hablar francés y no tenemos miedo de hablar otras lenguas, incluyendo el inglés (Ducharme, Fonseca, 2003: 5).

Es más, si admitimos que la voz de estos jóvenes recoge el sentir de muchos de sus coetáneos, la conciencia de pertenecer a una sociedad definida por la diversidad étnica y cultural se convierte en una plataforma de participación política acorde con otro proyecto social. El nuevo paradigma identitario debe conducir a una nueva concepción del nacionalismo quebequense inclusivo y edificado sobre la base de la diversidad. Ésta es, al menos para los firmantes del texto, la posición y el camino a seguir por las nuevas generaciones, como se dijo antes, surgidas y formadas en la estela de la ley 101. Acaso no sea inútil subrayar a este respecto la importancia simbólica que sigue revistiendo, entonces como ahora, el papel de la lengua en la autopercepción de la identidad. Ducharme y Fonseca comparten la trascendencia de ese patrimonio pero imprimen un matiz a su argumentación cuando defienden este bien colectivo: "La lengua francesa constituye el cimiento sobre el que debe concretarse la voluntad de vivir juntos. Por

\footnotetext{
${ }^{6}$ Nikolas Ducharme estudia una maestría en la ENAP y es presidente de la FEUQ (Federación Estudiantil Universitaria de Quebec). Frederico Fonseca militó activamente en varios organismos juveniles y actualmente trabaja en el sector público.

${ }^{7}$ Disposición provincial que obliga al uso del francés en la publicidad, en los espacios de trabajo, en la educación para los inmigrantes, y otros contextos oficiales.
} 
ende, la lengua ya debe dejar de ser considerada como un refugio o una muralla en contra de la asimilación, sino convertirse más bien en un orgullo a compartir con todos los nuevos quebequenses por venir" (ibid.: 19).

\section{Actitudes en perpetuo devenir}

Ahora bien, en esta historia de la inmigración en Quebec lo que los especialistas locales han analizado más detenidamente es la actitud de la sociedad de adopción frente al fenómeno y de ello se desprenden cambios cualitativos que van de una relativa hostilidad a una clara apertura.

El campo de las artes es uno de los terrenos donde la integración entre mayorías y minorías se produce cada vez con mayor naturalidad; los intercambios desembocan en apreciables aportaciones para la vida de la provincia. La presencia de escritores, dramaturgos y artistas plásticos en la actividad cultural es insoslayable tanto por su peso como por su calidad. Que se les conozca como "neoquebequenses" o bajo alguna de las múltiples y cambiantes etiquetas acuñadas al calor del debate científico o político, el paisaje sociocultural del Quebec actual no puede ser entendido sin la participación y el sello de esos actores, como dicen algunos especialistas, "venidos de otra parte" o esos "extranjeros de adentro". 8

Dada la complejidad de la situación que hemos venido describiendo, lo que convendría hacer sería acercarnos a ella desde tantas perspectivas como fuera necesario. Para ello hay que empezar por plantear que los esquemas que funcionaron en otros momentos ya resultan inoperantes y que a final de cuentas en su propio proceso las sociedades eligen preservar o abandonar ciertos rasgos de su herencia cultural. También habría que entender que es en ese devenir donde se inscriben o se amalgaman otros ingredientes cosechados en el camino en virtud del contacto entre los portadores de otras tradiciones y la nueva colectividad, que se convierte en protagonista de este proceso, y responsable de forjar su propio destino con los elementos a su alcance. Los parámetros (Europa y privilegiadamente Francia) que antaño servían para estudiar y comprender al Quebec francés ya perdieron parte de su vigencia; esta suerte de referencia vertical ahora podría arrojar una luz más productiva imprimiéndole un giro en sentido horizontal en cuanto que los actores que inciden en la construcción de una identidad en proceso comparten e interactúan en el mismo espacio social. Se trataría en cierto modo de privilegiar un esquema sincrónico para entender la realidad actual, en vez del acercamiento diacrónico que se practicó durante tanto tiempo.

\footnotetext{
${ }^{8}$ Ver el atinado estudio de Clément Moisan y Renate Hildebrand sobre la participación de los migrantes en la vida literaria quebequense de 1937 a 1997. Ces étrangers du dedans. Une histoire de l'écriture migrante au Québec. Montreal, Editions Nota Bene, 2001.

Sobre la misma temática, $c f$. Laura López Morales, "Más allá de los orígenes la nueva literatura quebequense", Anuario de Letras Modernas, vol. 12, México, UNAM, 2004, pp. 141-162.
} 
Si la alteridad encarnada por esas presencias ajenas suscitó durante algún tiempo desconfianza e inquietud en un pueblo que había interiorizado como una amenaza la confrontación con el "otro" anglófono, los procesos sociodemográficos fueron paulatinamente modificando el entramado sobre todo urbano de los principales núcleos poblacionales. A través de un análisis retrospectivo, lo que salta a la vista es que Montreal en particular, donde se genera gran parte de la actividad cultural de la provincia, es desde hace más de medio siglo una aglomeración claramente cosmopolita. El perfil que hoy define a la sociedad quebequense, y muy señaladamente a la de Montreal, fue construyéndose gracias a la apertura en la actitud de la gente, a las experiencias compartidas entre unos y otros tanto en los espacios laborales como en lugares públicos. Ésta es la percepción global de una realidad que, por supuesto, ofrece una serie de matices dignos de atención para evitar juicios simplificadores. Sin embargo, como afirma Gilles Bibeau:

Hoy se conocen mucho mejor los procesos de integración lingüística y social de los neoquebequenses, sus trayectorias en el mercado de trabajo, las categorías de empleo que ocupan, su nivel de ingresos (la imagen del inmigrante obrero ha sido remplazada por la del profesionista, del empresario y del citadino) y el papel que desempeñan las instituciones públicas como vectores de integración. También se sabe mucho más acerca de sus itinerarios migratorios, de las amplias redes de la diáspora y de la contribución de los neoquebequenses en la vida cultural colectiva, en literatura, en música, en danza, etc. En el crisol de nuestras diferencias se fabrica, como han demostrado los investigadores, identidades plurales, mestizadas, transculturales, entre los jóvenes de todos los orígenes que inventan una cultura urbana inédita que no es ni la de sus padres ni la del país receptor. La sociedad quebequense misma vive en su interior, a querer o no, la fluidez de las identidades, el desdibujamiento de las fronteras entre los grupos, el multilingüismo, las iglesias, los mercados étnicos, los matrimonios mixtos y muchas cosas más (2001: 226).

He aquí bien resumido el paisaje actual de una sociedad que no deja de aprender los nuevos modos de convivencia impuestos no sólo por la dinámica ligada a la globalización sino por la opción de puertas abiertas a la inmigración.

\section{Obras citadas}

BiBEAU, Gilles, 2002. "Accueillir 'l'autre' dans la distinction. Essai sur le Québec pluriel”. Denise LÉMIEUX, dir., Traité de la culture. Quebec: Presses de l'Université Laval. Pp. 229-240. (Les Éditions de l'IQRC)

Bouchard, Gérard, 2001, Genèse des nations et cultures du Nouveau Monde. Montreal: Boréal.

1999. La nation québécoise au futur et au passé. Montreal: vlb éditeur. 
Ducharme, Nicolás y Frederico FOnSECA, 2003. "Les Québécois à l'heure d'un nouveau paradigma identitaire”. Les Cahiers du 27 juin, vol. 1, núm. 1. Quebec.

HARVEY, Fernand. 1992. "Les communautés culturelles et le multiculturalisme: une comparaison des politiques québécoise et canadienne”. Jean-Michel LACROIX, dir., Métamorphose d'une utopie. París / Montreal: Presses de la Sorbonne Nouvelle / Tryptique.

LÉMIEUX, Denise, 2002. Traité de la culture. Quebec: Presses de l’Université Laval. (Les Éditions de l'IQRC)

SALÉE, Daniel. 1995. "Identité québécoise, identité autochtone et territorialité: entre les frontières subjectives et objectives de l'espace québécois". Alain-G. GAGNON y Alain NoËL, dirs., L'espace québécois. Montreal: Québec-Amérique.

TACHEREAU, Sylvie. 2002. "Migrations et relations ethniques". Denise LeMIEUX, dir., Traité de la culture. Quebec: Les Éditions de l'IQRC. Pp. 201-217. 